University of Wollongong

Research Online

Faculty of Engineering and Information

Faculty of Engineering and Information

Sciences - Papers: Part A

Sciences

$1-1-2013$

Impact of capacity value of renewable energy resources on RAPS system energy management

Y Tan

University of Wollongong

Kashem Muttaqi

University of Wollongong, kashem@uow.edu.au

Lasantha Meegahapola

University of Wollongong, lasantha.meegahapola@rmit.edu.au

Follow this and additional works at: https://ro.uow.edu.au/eispapers

Part of the Engineering Commons, and the Science and Technology Studies Commons

Research Online is the open access institutional repository for the University of Wollongong. For further information contact the UOW Library: research-pubs@uow.edu.au 


\title{
Impact of capacity value of renewable energy resources on RAPS system energy management
}

\author{
Abstract \\ Renewable energy resources are widely being utilised in remote area power supply (RAPS) systems. The \\ capacity value of renewable energy resources in a RAPS system indicates the ability of renewable energy \\ resources to serve the load demand in the RAPS systems. In this paper, the impact of capacity value of \\ renewable resources on energy management of a RAPS system, while maintaining system reliability, is \\ investigated. It is revealed that capacity value of renewable energy resources has direct influence on \\ RAPS system energy management. By utilising storage in conjunction with renewable energy resources, \\ the RAPS system can cater load demand while achieving a higher reliability. A case study based on a \\ remote village has shown that with the presence of a renewable energy resource with high capacity value \\ can meet the load demand with a relatively small storage system for energy balance while maintaining \\ the level of reliability target. Therefore, it is imperative to consider capacity value of renewable energy \\ resources to design a highly reliable RAPS system.
}

\section{Keywords}

management, renewable, value, resources, capacity, raps, impact, energy, system

\section{Disciplines}

Engineering | Science and Technology Studies

\section{Publication Details}

Y. Tan, K. M. Muttaqi \& L. Meegahapola, "Impact of capacity value of renewable energy resources on RAPS system energy management," in Renewable Power Generation Conference (RPG 2013), 2nd IET, 2013, pp. 1-4. 


\title{
IMPACT OF CAPACITY VALUE OF RENEWABLE ENERGY RESOURCES ON RAPS SYSTEM ENERGY MANAGEMENT
}

\author{
Y. Tan, K. M Muttaqi, L. Meegahapola \\ Endeavour Energy Power Quality and Reliability Center, School of Electrical, Computer \& Telecommunications Engineering, \\ University of Wollongong, Australia, Email: yt816@uowmail.edu.au
}

Keywords: Capacity Value, Energy Management, Remote Area Power Supply (RAPS) Systems, Renewable Energy.

\begin{abstract}
Renewable energy resources are widely being utilised in remote area power supply (RAPS) systems. The capacity value of renewable energy resources in a RAPS system indicates the ability of renewable energy resources to serve the load demand in the RAPS systems. In this paper, the impact of capacity value of renewable resources on energy management of a RAPS system, while maintaining system reliability, is investigated. It is revealed that capacity value of renewable energy resources has direct influence on RAPS system energy management. By utilising storage in conjunction with renewable energy resources, the RAPS system can cater load demand while achieving a higher reliability. A case study based on a remote village has shown that with the presence of a renewable energy resource with high capacity value can meet the load demand with a relatively small storage system for energy balance while maintaining the level of reliability target. Therefore, it is imperative to consider capacity value of renewable energy resources to design a highly reliable RAPS system.
\end{abstract}

\section{Introduction}

According to international energy agency report, 1.3 billion people worldwide do not have access to electricity and a billion more only have intermittent access [1]. The communities living in the remote and rural areas with no access to the main grid supply system are typically powered by separate power supply systems, which are commonly known as remote area power supply (RAPS) systems. This kind of isolated grid is highly recommended by the Energy Access Practitioner Network launched by the United Nations Foundation to ensure universal access to modern energy service [2]. Wind and solar energy are becoming popular for the use in RAPS systems. However, their intermittent nature has resulted in design and operational challenges. In particular, energy management is a challenging issue which may directly affect the reliability of the RAPS system.

Capacity value is defined as the additional load a system can serve by adding a new generator while maintaining the same system reliability level [11]. Effective load carrying capability (ELCC) is a metric to denote capacity value [3]. ELCC is determined based on the loss of load probability (LOLP). The LOLP is defined as the probability of not meeting the load demand by the generation. The loss of load expectation (LOLE) indicates the total time when demand is more than generation in a given time period, generally described by hours/year or days/10 years. The LOLP and the LOLE are two main reliability indicators used for power supply systems. Different methods for calculation of capacity value were presented in literature. The Garver method introduces a system character parameter to determine the ELCC with graphical aids [7]. The Z-method defines a $\mathrm{Z}$ factor, and keeps the Z-factor constant when additional generation and load are added to the system [5]. Chronological method described in [4] estimates the capacity value by computing capacity factor over appropriate time period. These methods aim to simplify the calculation process and reduce the computational burden using some assumptions. The ELCC/LOLE method is recommended in [11], which calculates the ELCC using generation and load time series in an iterative manner. The resolution of the data should not be greater than 1 hour in order to achieve robust result [10].

Energy management aims to balance the real power generation and demand in a power system. Reliability is an important objective of energy management in a power system, and a reliability target is usually set depending on the load requirements. In a RAPS system, reliability level should be maintained while energy management is carried out. The loss of power supply probability (LPSP) is intensively used as a criterion to indicate reliability in a RAPS system. In [12], unit size is optimised based on the LPSP requirement. In [6], by setting the LPSP target to zero, system cost is analysed to develop an optimal sizing of the RAPS system to make the system energy-sufficient and cost-effective. The LOLP is also in use which is abbreviated as the LLP in [8]. Storage systems are widely being used in RAPS systems $[6,8,12]$, and they play an important role in energy management by mitigating the impact of intermittency of renewable energy resources while enhancing the reliability.

This paper employs the ELCC/LOLE method to compute capacity value of renewable energy resources and investigates the impact of capacity value of renewable energy resources on RAPS system energy management. The minimum nominal capacity for the storage system is then determined, aiming for a highly reliable RAPS system.

\section{Component Modelling for the RAPS system}

A schematic diagram of a RAPS system is shown in Figure 1. An AC/DC converter interfaces the permanent magnet synchronous generator (PMSG) driven by a wind turbine to the DC bus. A DC/DC converter connects PV system to the DC bus. The wind generator and PV system are controlled to operate at their maximum power point. Dump load, which 
could be a space heating or water-heating system [13], and load are illustrated by a single load block shown in Figure 1. A RAPS system consisted of diesel generators has been considered as the base-model for this study. In order to determine the capacity value of renewable energy resources and the impact of capacity value on energy management, different RAPS system configurations are considered with different combinations of renewable energy generators and diesel generators.

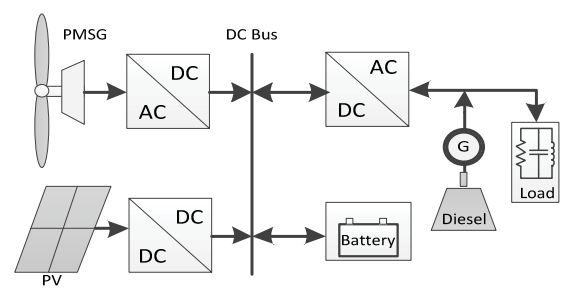

Figure 1: Schematic diagram of the target RAPS system

The lead-acid battery has been used as the main storage element to manage energy balance in the RAPS system. Since the purpose of this study is to investigate the impact of capacity value, only simple mathematical models have been used for the system components which are described in following subsections.

\subsection{Diesel generators}

Rated capacity and forced outage rate (FOR) are two key parameters of a conventional generator. Several generators usually work in combination to improve stability. The capacity outage probability table (COPT) [9] lists possibly unavailable capacity along with the probability that the corresponding outage capacity may occur. Each generator has two states: online and offline. In general, for $n$ generators, $C_{i}$ $(i=1,2, \ldots, n)$ and $f_{i}$ are the rated capacity and FOR of the $i^{\text {th }}$ generator respectively, $2^{n}$ combinations of operating states may occur and $2^{n}$ outage capacities can be determined by:

$$
\left(O_{1}, O_{2}, \ldots, O_{2}{ }^{n}\right)^{T}=A \cdot\left(C_{1}, C_{2} \ldots C_{n}\right)^{T}
$$

where $O_{j}$ refers to $j^{\text {th }}\left(j=1,2, \ldots, 2^{n}\right)$ outage capacity. Identical outage capacities may exist, they can be regarded as a single outage capacity and addition of their probabilities is the total probability for this outage capacity [9]. $A$ is an array with the dimension of $2^{n} \times n$ and each row of the array represents one of the $2^{n}$ possible operating states. The value of the $i^{\text {th }}$ element in a row depends on the $i^{\text {th }}$ generator's operating state. If the $i^{\text {th }}$ generator is offline, the $i^{\text {th }}$ element in the row is considered to be one, otherwise the element is zero.

The probability $P_{o j}$ for outage capacity $O_{j}$ is determined by:

$$
P_{o j}=\prod P_{i}
$$

where $P_{i}$ equals $f_{i}$ if the $i^{\text {th }}$ generator is offline (or the $i^{\text {th }}$ element in a row in $A$ is one). Otherwise $P_{i}$ equals to $\left(1-f_{i}\right)$. As an example, for two diesel generators operating in combination, and each rated at $10 \mathrm{~kW}$ with FOR being 0.02 , the COPT for these two generators is given in Table 1.

\begin{tabular}{|c|c|c|c|}
\hline Outage Capacity (kW) & 20 & 10 & 0 \\
\hline Probability (\%) & 0.04 & 3.92 & 96.04 \\
\hline
\end{tabular}

Table 1: COPT for generators $(10 \times 2 \mathrm{~kW}, \mathrm{FOR}=0.02)$

\subsection{Wind generator}

Manufacturers usually provide power curve for wind turbine generator to represent the actual relationship between power output and wind speed at hub height. The available specification for wind turbine generator generally lists discrete wind speeds and corresponding power output. In order to find out the power output for any wind speed, cubic spline interpolation functions are used to fit the curve $[6,8]$. A piecewise fitting technique is applied by separating the curve into $m$ subsections and each subsection fits to a cubic polynomial equation. The equation for $k^{\text {th }}(k=1,2, \ldots, m)$ subsection can be:

$$
P_{w k}(V)=a_{k} V^{3}+b_{k} V^{2}+c_{k} V+d_{k}, V_{k-1}<V<V_{k}
$$

where $P_{w k}(V)$ is the power output of the wind turbine at a wind speed of $V . V_{k}$ is the wind speed at which the curve is separated. $a_{k}, b_{k}, c_{k}, d_{k}$ are the polynomial coefficients. $V_{c i}=V_{0}$ is called the cut-in wind speed and $V_{c o}=V_{m}$ is the cut-out wind speed. When wind speed is beyond the range $\left[V_{c i}, V_{c o}\right]$, the wind turbine power output is zero.

\subsection{PV and battery modules}

Power output of PV modules can be expressed as below [8]:

$$
P_{s}=\eta \cdot A_{t} \cdot I
$$

where $\eta$ is the module conversion efficiency which is taken as $15 \%$ for this study. $A_{p}$ is the total area of PV modules. $I$ is the solar insolation on the surface of the PV module. The battery model given in [6] is used in this paper. During charging process, the following two cases can be considered.

1) For generation from diesel $P_{d}(t)$ is higher than load $P_{L}(t)$, the state of charge (SOC) at time $t$ is determined by:

$$
\begin{aligned}
\operatorname{SOC}(t) & =\operatorname{SOC}(t-1) \cdot(1-\sigma) \\
& +\left[P_{r}(t)+P_{d}(t)-P_{L}(t)\right] \cdot \eta_{\text {bat }} .
\end{aligned}
$$

2) For generation from diesel $P_{d}(t)$ is less than load $P_{L}(t)$, the SOC at time $t$ is determined by:

$$
\begin{aligned}
\operatorname{SOC}(t)= & \operatorname{SOC}(t-1) \cdot(1-\sigma) \\
& +\left\{P_{r}(t)-\left[P_{L}(t)-P_{d}(t)\right] / \eta_{\text {inv }}\right\} \cdot \eta_{\text {bat }} .
\end{aligned}
$$

During discharging process,

$\operatorname{SOC}(t)=\operatorname{SOC}(t-1) \cdot(1-\sigma)$

$$
-\left\{\left[P_{L}(t)-P_{d}(t)\right] / \eta_{\text {inv }}-P_{r}(t)\right\} \cdot \eta_{\text {bat }}
$$

where $P_{r}(t)$ is either wind generator or PV output. $\sigma$ is the self-discharge rate of batteries and is set to be $0.14 \%$ per day in this paper. Battery efficiency $\eta_{b a t}$ is set to 1 during discharging process and 0.8 during charging process. Inverter efficiency $\eta_{i n v}$ is used as $80 \%$. Battery capacity is determined using Equation (8), thus the two constraints: nominal capacity $C_{r}$ and maximum permissible depth of discharging (DOD) are satisfied.

$$
D O D \times C_{r} \leq S O C(t) \leq C_{r}
$$

\section{Energy management strategy}

The real power balance of the RAPS system can be represented as:

$$
P_{d}(t)+P_{r}(t) \pm P_{b}(t)-P_{L}(t)=0
$$

Balance between generation and load must be maintained instantaneously in a reliable RAPS system. Due to the intermittency of wind and solar energy resources, battery 
plays a key role in power balancing. The surplus energy during low load period will be stored for peak load period. Therefore, if power surplus exists, batteries act as a load to absorb surplus power $P_{b}(t)$ and store the power until a power deficit occurs in the RAPS system. The capacity of the batteries is finite, so if it is full, then surplus power can be consumed by dump load. Contrarily, if power generation is insufficient to meet load demand, then batteries will be discharged to mitigate the power deficit. These two operating conditions for batteries are represented by negative and positive signs in Equation (9). If batteries cannot meet the demand, load shedding is implemented, resulting in a 'loss of load' case which will ultimately increase the LOLE, hence reduce the system reliability.

With the presence of a renewable energy resource of higher capacity value, the renewable resource can supply power when load demand increases, or generation and load are highly correlated. Therefore, Equation (9) can be satisfied during most of the time even without battery element $P_{b}(t)$, while exhibiting a higher reliability level. However, if a renewable energy resource of lower capacity value exists in the RAPS system, the generation is poorly correlated to the load. Although surplus energy exists in certain situations, power deficit may also occur quite often and hence storage systems must be used for energy management. Therefore, under such situations, energy stored in batteries during the time periods of surplus energy should be discharged to mitigate the power deficit. The nominal capacity of batteries should be large enough so that surplus energy can be stored and this may be sufficient to provide the energy requirement in order to eliminate the possibility of "loss of load" case while improving reliability. Larger nominal capacity may be required for batteries to enhance reliability with renewable energy resources of lower capacity value. The minimum nominal capacity for batteries can be determined to achieve the level of reliability target.

\section{Case study}

A case study has been carried out considering the wind and solar insolation data for a remote village. A sample of the annual hourly wind generator power output, PV power output and load profiles at the site are shown in Figure 2.

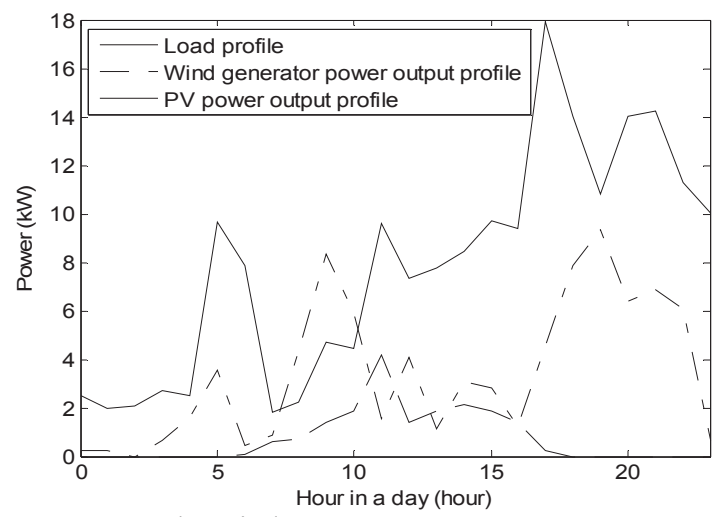

Figure 2: Hourly wind generator power output, PV power output, and load profiles in a day

As shown in Figure 2, neither the wind generator nor the PV can meet the load demand alone. Thus, diesel generators are utilised. The system configurations investigated for the RAPS system are listed below.

1) Only diesel generators $(10 \mathrm{~kW} \times 3)$

2) Diesel generators $(10 \mathrm{~kW} \times 3)$ and wind turbine $(10 \mathrm{~kW})$

3) Diesel generators $(10 \mathrm{~kW} \times 3)$ and PV $(10 \mathrm{~kW})$

4) Diesel generators $(10 \mathrm{~kW} \times 2)$, wind turbine $(10 \mathrm{~kW})$, and batteries

5) Diesel generators $(10 \mathrm{~kW} \times 2)$, PV $(10 \mathrm{~kW})$ and batteries.

The system is designed with LOLE of 1 day per 10 years, which is 2.4 hours per year. The first three scenarios determine the capacity value of wind and solar energy by using following procedure: Firstly, considering scenario 1, the system supplies power to the load at high reliability level (LOLE is less than 2.4 hours). Constant load $\Delta L$ is added to load time series across each hour iteratively until the annual peak load increases by $20 \%$. During this process, the LOLEs for each load time series are computed. The relationship between peak load and corresponding LOLEs is shown by the solid curve in Figure 3. Secondly, renewable generation time series is added to load time series as negative load for scenarios 2 and 3. The LOLEs for each new load time series are then determined. The impact of additional generation on the LOLE is shown by the other two curves in Figure 3.

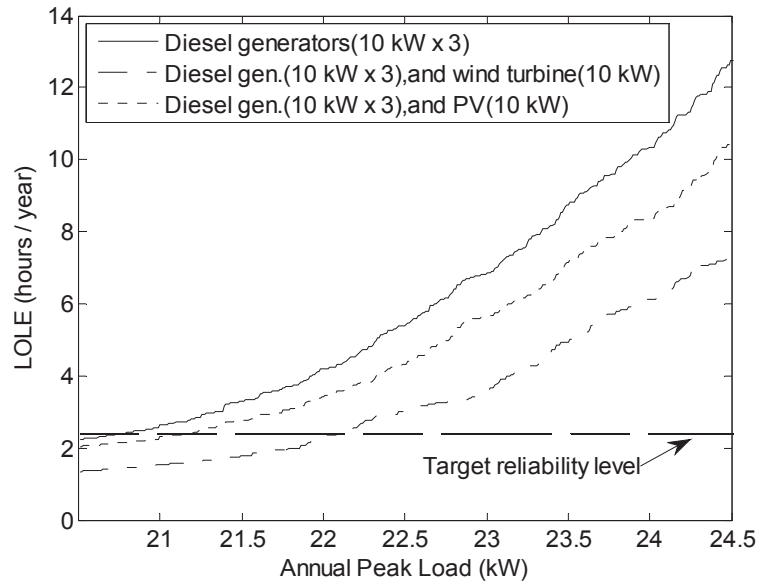

Figure 3: Impact of additional generation on reliability

Due to the addition of renewable generation, system becomes more reliable at each load level and extra load can be served while maintaining the same reliability level. The amount of the extra load (i.e. capacity value), can be determined by the distance between the curve representing system with renewable energy and the curve representing original system at the required reliability level (i.e. LOLE of 2.4 hours per year). In this case the capacity value of the wind system is larger than the capacity value of the PV system. The curves indicate that system with wind generation is more reliable than system with PV under each load level. Scenarios 1 to 3 operate at high reliability level under the load profile at the remote village.

In scenarios 4 and 5, one diesel generator was eliminated, and subsequently system reliability has substantially decreased below the level of reliability target. As an example, LOLEs have increased more than 40 hours per year (see Figure 4 for zero battery capacity). If batteries are installed, reliability can be improved as demonstrated in Figure 4. When nominal 
capacity of batteries increases, LOLE decreases. Particularly, the batteries of $7.5 \mathrm{kWh}$ can reduce the LOLE for system with wind energy to 1.9 hours per year. If the same batteries are applied to the system with solar energy, the LOLE is only reduced to 3.4 hours per year, and fail to meet the level of reliability target. The increase in capacity of batteries brings down the LOLE to predesigned level. In this case, batteries of $8.5 \mathrm{kWh}$ fulfil the reliability requirement, and LOLE becomes 2 hours per year. As shown in scenarios 2 and 3 by utilising another diesel generator (i.e. all 3 diesel generators are now in operation), it can eliminate the battery requirement while maintaining reliability target. Therefore, for different energy resources, lower capacity value contributes to less reliable energy balancing performance, requiring larger nominal capacity for batteries to achieve the reliability target.

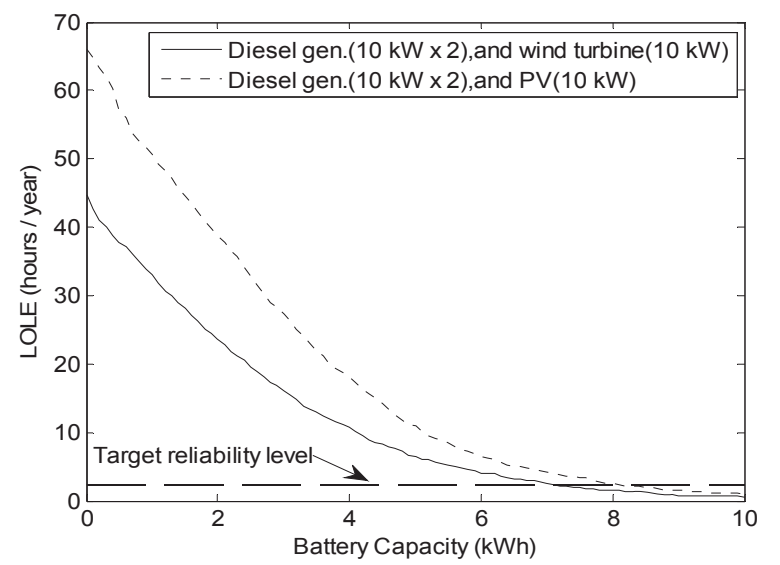

Figure 4: Impact of nominal capacity of batteries on reliability considering wind and solar energy

Furthermore, the impact of different capacity values for a single renewable energy resource was also investigated. The wind speed at the site is scaled to yield variable capacity values. The corresponding LOLEs for different nominal battery capacities are found under scaled wind speed profiles. According to Figure 5, system with wind energy of larger capacity value is more reliable at each battery size and tends to require less nominal capacity for batteries to meet the reliability target.

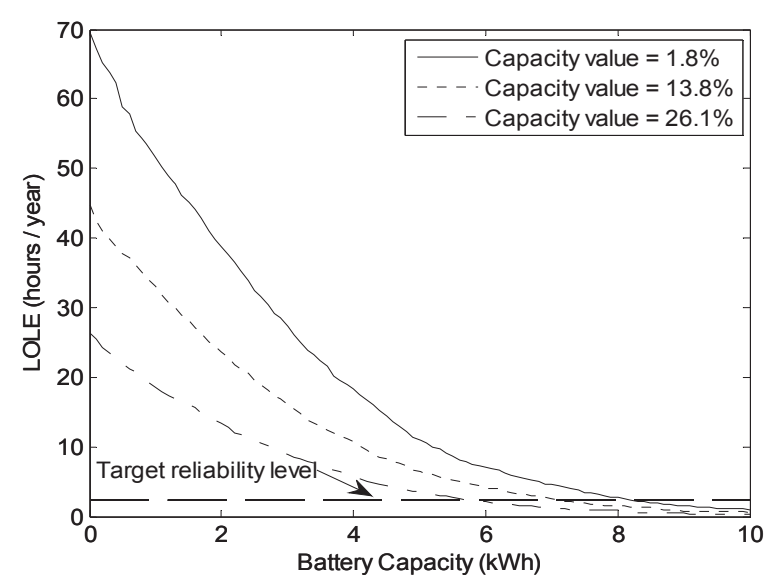

Figure 5:Impact of nominal capacity of batteries on reliability considering wind energy of different capacity values

\section{Conclusions}

This paper investigates the impact of capacity value of renewable energy resources on RAPS system energy management. The ELCC/LOLE method has been utilised to compute capacity value of renewable energy resources. The case study carried out based on a RAPS system in a remote village has shown that capacity value has a direct influence on energy management as the size of the storage system depends on the capacity value of the renewable energy resource used in the RAPS system. A renewable energy resource with high capacity value tends to balance generation and load at higher reliability level, and smaller nominal capacity is required for storage to improve reliability to a target level. Therefore, it is essential to consider the capacity value of renewable energy resources while planning for a highly reliable RAPS system.

\section{References}

[1] Energy Access Practitioner Network: Towards Achieving Universal Energy Access by 2030 [Online]. Available: http://sustainableenergyforall.org/images/content/FINAL\%20E SG\%20ALL.pdf

[2] International Energy Agency, World Energy Outlook 2012, Paris: OECD/IEA, (2012).

[3] M. Amelin, "Comparison of Capacity Credit Calculation Methods for Conventional Power Plants and Wind Power," Power Systems, IEEE Transactions on, vol. 24, pp. 685-691, (2009).

[4] R. M. G. Castro and L. A. F. M. Ferreira, "A comparison between chronological and probabilistic methods to estimate wind power capacity credit," Power Systems, IEEE Transactions on, vol. 16, pp. 904-909, (2001).

[5] K. Dragoon and V. Dvortsov, "Z-method for power system resource adequacy applications," Power Systems, IEEE Transactions on, vol. 21, pp. 982-988, (2006).

[6] S. Diaf, D. Diaf, M. Belhamel, M. Haddadi, and A. Louche, "A methodology for optimal sizing of autonomous hybrid PV/wind system," Energy Policy, vol. 35, pp. 5708-5718, (2007).

[7] L. L. Garver, "Effective Load Carrying Capability of Generating Units," Power Apparatus and Systems, IEEE Transactions on, vol. PAS-85, pp. 910-919, (1966).

[8] F. O. Hocaoğlu, Ö. N. Gerek, and M. Kurban, "A novel hybrid (wind-photovoltaic) system sizing procedure," Solar Energy, vol. 83, pp. 2019-2028, (2009).

[9] A. H. Hashim, S. E. H. Chan, M. T. Au, "A combined probabilistic and deterministic method for an improved capacity outage probability table synthesis using monte carlo methods", in Energy and Environment, 2009. ICEE 2009. $3^{\text {rd }}$ International Conference on, pp. 140-144, (2009)

[10] B. Hasche, A. Keane, and M. O'Malley, "Capacity Value of Wind Power, Calculation, and Data Requirements: the Irish Power System Case," Power Systems, IEEE Transactions on, vol. 26, pp. 420-430, (2011).

[11] A. Keane, M. Milligan, C. J. Dent, B. Hasche, C. D'Annunzio, K. Dragoon, H. Holttinen, N. Samaan, L. Soder, and M. O'Malley, "Capacity Value of Wind Power," Power Systems, IEEE Transactions on, vol. 26, pp. 564-572, (2011).

[12] P. K. Katti and M. K. Khedkar, "Alternative energy facilities based on site matching and generation unit sizing for remote area power supply," Renewable Energy, vol. 32, pp. 13461362, 2007.

[13] N. Mendis, K. M. Muttaqi, S. Sayeef, and S. Perera, "Control coordination of a wind turbine generator and a battery storage unit in a Remote Area Power Supply system," in Power and Energy Society General Meeting, 2010 IEEE, 2010, pp. 1-7. 